\section{Think A-Head Campaign of Image Gently: Shared Decision-Making in Pediatric Head Trauma}

(D) N. Kadom, DB.L. Vey, (DD.P. Frush, (D).S. Broder,

(D) K.E. Applegate, and Members of the Image Gently Think

A-Head Campaign Committee

W hen children present with head trauma, as with any imaging examination, it is necessary to consider the risks, costs, and benefits of testing. In many instances of pediatric head trauma, imaging studies are used for "confirming" or "excluding" certain diagnoses. ${ }^{1}$ However, imaging tests, specifically radiographs ( $\mathrm{x}$-rays) and CT expose children to ionizing radiation, which, at relatively high doses (much higher than typical doses from diagnostic imaging), does have a small increased risk of cancer. ${ }^{2}$ For children who experience head injury, there are now scientifically validated criteria that can help decide whether imaging tests are beneficial or can be avoided. This type of information is essential when providers discuss the use of imaging tests and other options with caregivers and patients during the shared decision-making process. Of note, the recommendations discussed in this article do not pertain to patients with head trauma in suspected child abuse.

Diagnostic imaging following head trauma serves several purposes: diagnosis, treatment planning, prognosis, and reassurance. In some cases, imaging of subtle injuries not requiring intervention can be avoided (Canadian CT Head Rule; Pediatric Emergency Care Applied Research Network [PECARN]). Clinical Decision Rules (CDRs) are intended to inform management partly by obviating unhelpful diagnostic imaging; clinical outcomes of patients are based on history and examination features. In pediatric head trauma, it is understood that children meeting low-risk criteria for head injury do not need diagnostic imaging because they do not require any additional interventions, such as additional observation, or neurosurgical procedures to achieve good neurologic outcomes. ${ }^{3}$

Concerns by caregivers, patients, and medical providers about potential carcinogenic effects of radiation exposure, even given relatively low doses during medical imaging, must be weighed against the risk of missing a clinically significant head injury that could harm a child if CT is deferred. Parents, patients, and caregivers may over- or underestimate the risk of radiation from CT relative to the risk of an undiagnosed brain injury. ${ }^{4}$ Physicians should use scientific evidence to estimate injury risk (using the Clinical Decision Rules described below), and the best available evidence about the radiation risk of CT to assist in shared decision-making. ${ }^{5}$

When one counsels patients, it is important to remember that the current knowledge on radiation risk for a given imaging study should not be downplayed or overemphasized to manipulate families into making what the physician believes to be the "right" decision. Rather, the best available scientific evidence should be used to estimate the risk of missing an important injury without imaging and the benefit

http://dx.doi.org/10.3174/ajnr.A5718 of defining the extent of a known significant injury with imaging. The imaging test benefit may vary for each patient scenario. The benefit of reassurance following normal CT findings may also be an important consideration. The Image Gently Alliance (www.imagegently.org) multispecialty, collaborative "Think A-Head" campaign (Figure) promotes the use of evidence-based guidelines when deciding whether children with head trauma need imaging and, if so, which imaging test (technique) would be appropriate.

Appropriate imaging modalities available for evaluating the head in children with trauma include radiography, CT, and MR imaging. Existing evidence-based clinical decision rules refer to the use of CT, which is widely available and can be accessed quickly in most US medical centers. Increasingly fast CT examination times obviate sedation in most cases, which is an important consideration, especially for serial patient evaluations in the emergency setting. MR imaging is not established for routine use in acute pediatric brain trauma yet, though several studies have validated the ability of MR imaging to detect relevant pathology and have shown the feasibility of rapid MR imaging protocols. ${ }^{6-8}$ The use of radiographs in minor pediatric head trauma is controversial. In patients with linear skull fractures on radiographs and who are asymptomatic, there may still be small intracranial hemorrhages, but these would not require neurosurgical intervention. ${ }^{9}$ In children younger than 2 years of age with minor head trauma, there is a higher risk of skull fracture, but neuro-observation without initial CT imaging is considered safe. ${ }^{10}$ In general, skull radiographs should not be used routinely in children with minor head trauma. ${ }^{10}$ The American College of Radiology appropriateness criteria for head trauma in children provide further information about the appropriate choice of imaging studies, depending on clinical scenarios. ${ }^{11}$

\section{Clinical Decision Rules}

Clinical Decision Rules are clinical care guides intended to improve the appropriateness of care based on scientific evidence. CDRs reduce the use of unnecessary advanced testing (with associated cost, time, and risks such as further downstream investigations of incidental imaging findings and ionizing radiation) without compromising patient outcomes. CDRs typically use readily available information from the history and physical examination to risk-stratify patients. Other benefits of CDRs include the ability to create standardized care pathways, which can help reduce variation of practice by individual providers. In the case of traumatic brain injury, CDRs are expected to detect serious injury requiring intervention. Some rules by intention attempt to detect all injuries, regardless of the requirement for treatment, while others intentionally do not aim to detect injuries that would not progress or require explicit therapy, such as minimally displaced skull fractures. In general, an increase in the diagnostic sensitivity of a rule results in reduced specificity, usually leading to only a small-tomoderate reduction of imaging/testing use. Rules that ultimately achieve clinical adoption usually have a sensitivity for serious injury exceeding $99 \%$, with more modest specificity (often $60 \%-$ $70 \%$ ) and reductions in imaging use (of $3 \%-40 \%){ }^{12}$

Many decision rules have been tested for validity in specific populations, such as children. ${ }^{13,14}$ Most professional medical societies 


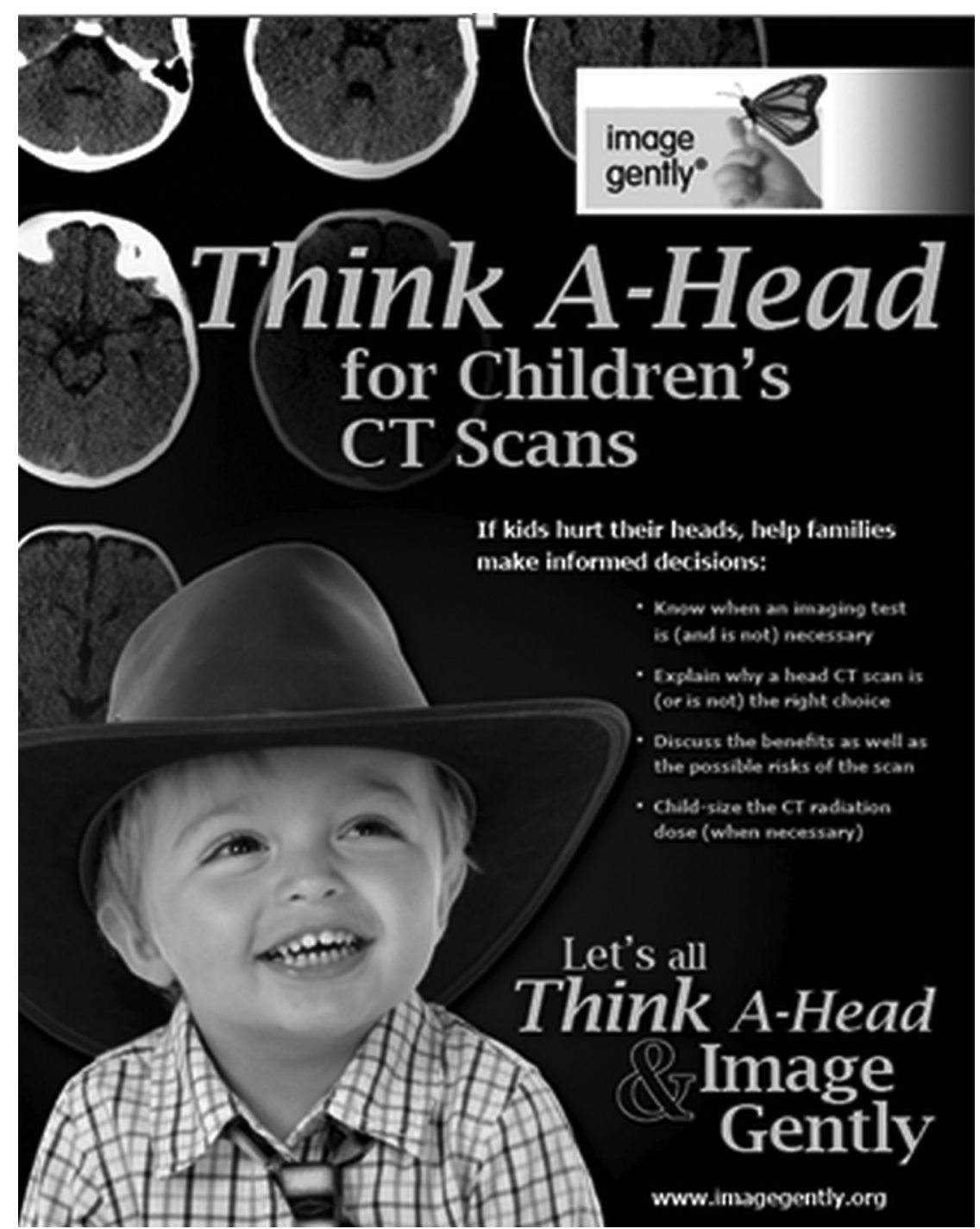

FIGURE. The Think A-Head campaign poster (www.imagegently.org). Poster design courtesy of the American Society of Radiologic Technologists.

endorse decision rules and help inform health care professionals of their existence. Locally, processes should be in place to enable training and promote compliance of care providers with decision rules that were locally adopted. Ideally, the health system should support quality monitoring and take opportunities to share stories of "harm and charm" to foster further improvement in care. Finally, medical providers and patient safety organizations can collaborate to share the best practice information so that parents and caregivers of children become partners in the care process, as promoted by the Choosing Wisely Campaign (www.choosingwisely.org).

For pediatric head trauma, several important decision rules have been developed and validated during the past 15 years (Tables 1 and 2): PECARN; the Canadian Assessment of Tomography for Childhood Head injury (CATCH); and the Children's Head injury Algorithm for the prediction of Important Clinical Events (CHALICE).

\section{Pediatric Emergency Care Applied Research Network}

The strength of the PECARN decision rule is that it identifies children who are at low risk for brain injury and do not need brain imaging with a sensitivity of $100 \% \cdot{ }^{15}$ These results are based on a multicenter prospective cohort study performed in 42,412 patients younger than 18 years of age and with a Glasgow Coma Scale (GCS) score of 14-15. The study yielded several clinical criteria that were predictive of clinically important traumatic brain injury. The study showed, with a $99.95 \%-100 \%$ negative predictive value, ${ }^{16,17}$ that children without clinical criteria for clinically important traumatic brain injury did not need neuroimaging. In the study, application of the PECARN rule could have reduced CT use by approximately $20 \%$ by identifying patients at extremely low risk of clinically important traumatic brain injury. ${ }^{16}$ Advantages of the PECARN decision tool over other decision tools include the PECARN rule being validated and the validation cohort including $20 \%$ of children younger than 2 years of age. ${ }^{16,18}$

\section{Canadian Assessment of Tomography for Childhood Head Injury}

CATCH guidelines are based on a prospective multicenter cohort study performed in 3866 patients younger than 16 years of age with a GCS score of 13-15. These guidelines identified 7 risk factors for the presence of brain injury on CT scans in children with minor head injury with $98.1 \%$ sensitivity (95\% confidence interval, $94.6 \%-99.4 \%)$ and $50.1 \%$ specificity $(95 \%$ confidence interval, $48.5 \%-51.7 \%){ }^{19}$

\section{Children's Head Injury Algorithm for the Prediction of Important Clinical Events}

CHALICE guidelines were published in $2006^{20}$ and are the result of a prospective multicenter cohort study in England, performed in patients 16 years of age and younger. The goal of this study was to derive a decision rule to aid in identification of children at risk who should undergo CT of the brain. The rule was applied to children regardless of the GCS score and was shown to have a sensitivity of $98 \%$ (95\% confidence interval, $96 \%-100 \%$ ) and a specificity of $87 \%$ ( $95 \%$ confidence interval, $86 \%-87 \%$ ) for the prediction of clinically significant head injury. ${ }^{20}$

\section{Risks}

The most widely adopted decision rule in children is the PECARN rule, probably because it is the only rule that has been validated in children. Of note, the PECARN rule has been shown to have a negative predictive value of $100 \%$, meaning that the likelihood of negative head CT findings in a child meeting the PECARN lowrisk criteria is $100 \%$. This means that there will still be a sizeable 


\begin{tabular}{|c|c|c|}
\hline PECARN & CATCH & CHALICE \\
\hline \multicolumn{3}{|l|}{ Mechanism of injury } \\
\hline $\begin{array}{l}\text { Severe mechanism of injury (MVC with patient } \\
\text { ejection, death of another passenger, or } \\
\text { rollover; pedestrian/bicyclist without } \\
\text { helmet struck by motorized vehicle; falls } \\
>1.5 \mathrm{~m} \text { [if younger than } 2 \mathrm{yr} \text {, fall }>0.9 \mathrm{~m} \text { ]; } \\
\text { head struck by high-impact object) }\end{array}$ & $\begin{array}{l}\text { Dangerous mechanism of } \\
\text { injury (eg, MVC; fall from } \\
\text { elevation of } \geq 3 \text { feet }[\geq 0.91 \mathrm{~m}] \\
\text { or } 5 \text { stairs; fall from } \\
\text { bicycle with no helmet). }\end{array}$ & $\begin{array}{l}\text { High-speed road traffic collision: } \\
\text { pedestrian, cyclist, occupant ( }>40 \text { miles } / \mathrm{h} \\
\text { or } 64 \mathrm{~km} / \mathrm{h} \text { ); fall }>3 \mathrm{~m} \text { in height; high-speed } \\
\text { injury from projectile or object }\end{array}$ \\
\hline \multicolumn{3}{|l|}{ History } \\
\hline Any or suspected LOC & History of worsening headache & Witnessed LOC $>5 \mathrm{~min}$ \\
\hline History of vomiting & & $\begin{array}{l}\geq 3 \text { Vomits after head injury (discrete } \\
\text { episodes) }\end{array}$ \\
\hline If age younger than 2 years & & Amnesia (anterograde/retrograde $>5 \mathrm{~min}$ ) \\
\hline $\mathrm{LOC} \geq 5 \mathrm{sec}$ & & Suspicion of nonaccidental injury \\
\hline Not acting normally per parent & & Seizure in patient with no history of epilepsy \\
\hline \multicolumn{3}{|l|}{ Physical examination } \\
\hline Clinical signs of basilar skull fracture & GCS $<15$, two hours after injury & $\begin{array}{l}\text { GCS }<14 \text {, pediatric GCS }<15 \text { if younger } \\
\text { than } 1 \text { yr of age }\end{array}$ \\
\hline If younger than 2 years age: & Irritability on examination & $\begin{array}{l}\text { Abnormal drowsiness (more than that } \\
\text { expected by examining doctor) }\end{array}$ \\
\hline Palpable or unclear skull fracture & Any sign of basal skull fracture & Positive focal neurology \\
\hline \multirow{3}{*}{$\begin{array}{l}\text { Occipital, parietal, or temporal scalp hematoma } \\
\text { Large boggy scalp hematoma }\end{array}$} & Suspected open or depressed & Signs of basal skull fracture \\
\hline & skull fracture & $\begin{array}{l}\text { Suspicion of penetrating or depressed skull } \\
\text { injury or tense fontanelle }\end{array}$ \\
\hline & & $\begin{array}{l}\text { Presence of bruise/swelling/laceration }>5 \mathrm{~cm} \\
\text { if younger than } 1 \mathrm{yr} \text { of age }\end{array}$ \\
\hline
\end{tabular}

Note:-MVC indicates motor vehicle collision; LOC, loss of consciousness.

Table 2: Comparison of reported statistics for CATCH, CHALICE, and PECARN rules

\begin{tabular}{lccl}
\hline Decision Rule & Sensitivity $(95 \% \mathrm{Cl})$ & Specificity $(95 \% \mathrm{Cl})$ & \multicolumn{1}{c}{ Reference } \\
\hline CATCH & $98.1 \%(94.6 \%-99.4 \%)$ & $50.1 \%(48.5 \%-51.7 \%)$ & Osmond et al $2010^{19}$ \\
CHALICE & $98 \%(96 \%-100 \%)$ & $87 \%(86 \%-87 \%)$ & Dunning et al $2006^{20}$ \\
PECARN & $100 \%(84 \%-100 \%)$ & $62 \%(59 \%-66 \%)$ & Babl et al 2014 \\
& \multicolumn{2}{c}{ NPV $=99.95 \%-100 \%$} & Kuppermann et al $2009^{16}$ \\
& & & Mihindu et al $2014^{17}$ \\
\hline
\end{tabular}

Note:-NPV indicates negative predictive value.

percentage of children who meet the clinical criteria for CT imaging according to PECARN but who will not have imaging findings. For example, Mihindu et $\mathrm{al}^{17}$ found, after retrospectively applying the PECARN criteria, that $85 \%$ of CTs that were indicated per PECARN had negative findings; only $15 \%$ had positive findings; and of these, most did not require any medical interventions. Both CHALICE and CATCH rules may miss clinically important traumatic brain injury. In a comparison study, it was shown that the median likelihood for CATCH and CHALICE to miss important traumatic brain injury was $4 \%{ }^{3}$

Using tools to increase physician compliance can aid in successful adoption of CDRs in clinical practice. For example, at a regional level I trauma center, the emergency department achieved a 95\% compliance with the PECARN rule regarding the use of CT in children with head trauma. This could be achieved using a provider scorecard and a peer-learning feedback system. ${ }^{21}$ Practices and institutional consensus of relevant stakeholders should determine whether decision rules are needed and which rules are the most appropriate. Auditing both impact and adherence to rules should also be part of this process.

\section{CONCLUSIONS}

All 3 CDRs for pediatric traumatic head injury describe high sensitivity with low specificity. This diagnostic performance of the
CDRs should not be surprising for the clinical scenario of head trauma in which it is critical not to miss this injury. The most commonly used decision rule in the United States today is the PECARN rule.

\section{The Think A-Head Collaborative Campaign by Image Gently}

The Image Gently Alliance, American Academy of Pediatrics, American College of Emergency Physicians, American Association of Neurologic Surgeons/Congress of Neurologic Surgeons Joint Section on Pediatric Neurosurgery, and other allied medical organizations launched the Think A-Head campaign to help providers appropriately obtain and perform CT in children with minor head injuries (www.imagegently.org/Procedures/Minor-CTin-Head-Injuries). The effort will also equip providers and parents with resources to help them communicate effectively about when CT may be the best option for a proper diagnosis and provide balanced information and resources on medical radiation use and potential risks in children (www.imagegentlyparents.org; www.imagegentlyproviders.org).

The Think A-Head campaign provides tools and resources to accomplish the following (Figure):

- Help providers ensure that ordering patterns comply with latest evidence-based medical guidelines.

- Help providers explain to parents/caregivers why an imaging scan is (or is not) necessary.

- Help parents ask questions to better inform decision-making if their child is prescribed a head CT scan.

- Help imaging professionals use an appropriate examination radiation dose. 


\section{REFERENCES}

1. Barrett TW, Rising KL, Bellolio MF, et al. The 2016 Academic Emergency Medicine Consensus Conference, "Shared Decision Making in the Emergency Department: Development of a Policy-relevant Patient-centered Research Agenda" Diagnostic Testing Breakout Session Report. Acad Emerg Med 2016;23:1354-61 CrossRef Medline

2. Pearce MS, Salotti JA, Little MP, et al. Radiation exposure from CT scans in childhood and subsequent risk of leukaemia and brain tumours: a retrospective cohort study. Lancet 2012;380:499-505 CrossRef Medline

3. Easter JS, Bakes K, Dhaliwal J, et al. Comparison of PECARN, CATCH, and CHALICE rules for children with minor head injury: a prospective cohort study. Ann Emerg Med 2014;64:145-52, 152.e1-5 CrossRef Medline

4. Lee CI, Haims AH, Monico EP, et al. Diagnostic CT scans: assessment of patient, physician, and radiologist awareness of radiation dose and possible risks. Radiology 2004;23:393-98 Medline

5. Lam DL, Larson DB, Eisenberg JD, et al. Communicating potential radiation-induced cancer risks from medical imaging directly to patients. AJR Am J Roengtenol 2015;205:962-70 CrossRef Medline

6. Cohen AR, Caruso P, Duhaime AC, et al. Feasibility of "rapid" magnetic resonance imaging in pediatric acute head injury. Am J Emerg Med 2015;33:887-90 CrossRef Medline

7. Mehta $\mathrm{H}$, Acharya J, Mohan AL, et al. Minimizing radiation exposure in evaluation of pediatric head trauma: use of rapid MR imaging. AJNR Am J Neuroradiol 2016;37:11-18 CrossRef Medline

8. Sheridan DC, Newgard CD, Selden NR, et al. QuickBrain MRI for the detection of acute pediatric traumatic brain injury. J Neurosurg Pediatr 2017;19:259-64 CrossRef Medline

9. Erlichman DB, Blumfield E, Rajpathak S, et al. Association between linear skull fractures and intracranial hemorrhage in children with minor head trauma. Pediatr Radiol 2010;40:1375-79 CrossRef Medline

10. Arneitz C, Sinzig M, Fasching G. Diagnostic and clinical management of skull fractures in children. J Clin Imaging Sci 2016;6:47 CrossRef Medline

11. Palasis S, Saigal G, Singer AD, et al. ACR Appropriateness Criteria head trauma-child. J Am Coll Radiol 2014;11:939-47 CrossRef Medline
12. Stiell IG, Wells GA. Methodologic standards for the development of clinical decision rules in emergency medicine. Ann Emerg Med 1999; 33:437-47 CrossRef Medline

13. Stiell IG, Greenberg GH, Wells GA, et al. Prospective validation of a decision rule for the use of radiography in acute knee injuries. JAMA 1996;275:611-15 Medline

14. Stiell IG, Greenberg GH, Wells GA, et al. Derivation of a decision rule for the use of radiography in acute knee injuries. Ann Emerg Med 1995;26:405-13 CrossRef Medline

15. Babl FE, Lyttle MD, Bressan S, et al; PREDICT research network. A prospective observational study to assess the diagnostic accuracy of clinical decision rules for children presenting to emergency departments after head injuries (protocol): the Australasian Paediatric Head Injury Rules Study (APHIRST). BMC Pediatr 2014;14:148 CrossRef Medline

16. Kuppermann N, Holmes JF, Dayan PS, et al; Pediatric Emergency Care Applied Research Network (PECARN). Identification of children at very low risk of clinically-important brain injuries after head trauma: a prospective cohort study. Lancet 2009;374:1160-70; Erratum in: Lancet 2014;383:308 CrossRef

17. Mihindu E, Bhullar I, Tepas J, et al. Computed tomography of the head in children with mild traumatic brain injury. Am Surg 2014; 80:841-43 Medline

18. Lyttle MD, Crowe L, Oakley E, et al. Comparing CATCH, CHALICE and PECARN clinical decision rules for paediatric head injuries. Emerg Med J 2012;29:785-94 CrossRef Medline

19. Osmond MH, Klassen TP, Wells GA, et al; Pediatric Emergency Research Canada (PERC) Head Injury Study Group. CATCH: a clinical decision rule for the use of computed tomography in children with minor head injury. CMAJ 2010;182:341-48 CrossRef Medline

20. Dunning J, Daly JP, Lomas JP, et al; Children's head injury algorithm for the prediction of important clinical events study group. Derivation of the children's head injury algorithm for the prediction of important clinical events decision rule for head injury in children. Arch Dis Child 2006;91:885-91 CrossRef Medline

21. Jain S, Frank G, McCormick K, et al. Impact of physician scorecards on emergency department resource use, quality, and efficiency. $P e-$ diatrics 2015;136:e670-79 CrossRef Medline 